\title{
Deactivation and Regeneration of Nickel-Based Catalysts for Steam-Methane Reforming
}

\author{
Seyed Meysam HASHEMNEJAD, Matin PARVARI* \\ School of Chemical Engineering, Iran University of Science and Technology, Tehran, Iran
}

\begin{abstract}
The deactivation of nickel catalysts used in Arak and Razi petrochemical complexes followed by catalyst regeneration was evaluated. The characterization of the different structures was made by powder X-ray diffraction (XRD), scanning electron microscopy (SEM), energy dispersive X-ray spectroscopy (EDS), transmission electron microscopy (TEM), and carbon \& sulfur analyzer. The Ni particle size was estimated from XRD patterns and TEM graphs. The agglomeration of nickel particle and the poison by sulfur components were recognized as the main reasons in deactivation of Arak and Razi catalysts, respectively. The activity of the used catalysts before and after regeneration was measured on methane steam reforming at a $\mathrm{CH}_{4}: \mathrm{H}_{2} \mathrm{O}$ ratio of $1: 3$ at $850{ }^{\circ} \mathrm{C}$. The regeneration processes for Arak and Razi samples were performed with $\mathrm{CO}_{2}$ as an oxidative atmosphere and steam as a regenerating agent, respectively. The results show that, (1) no residual sulfur components were on the regenerated Razi catalyst surface without changing the structure of the catalyst and the regenerated catalyst has gained $80 \%$ of its catalytic activity, and that (2) the nickel particle size of regenerated Arak specimen decreased remarkably as measured by Debye-Scherrer equation from XRD patterns. TEM images were in agreement with the XRD results and indicated a decrease in nickel particle size of regenerated catalyst. Additionally, in both regenerated catalysts all the coke on the surface of the support was eliminated after regeneration.
\end{abstract}

Key words: nickel catalyst; steam reforming; deactivation; sintering; sulfur poisoning; regeneration CLC number: O643 Document code: A

Hydrogen or mixtures of hydrogen, carbon monoxide, and carbon dioxide (synthesis gas) are used extensively in a wide range of industrial processes [1]. Hydrogen is predicted to become a major source of energy in the future. It is an important raw material in the chemical and petroleum industries; large quantities are used in the manufacture of ammonia and methanol and in a variety of petroleum hydro treatment processes [2,3]. Methane can be converted into synthesis gas by steam reforming, $\mathrm{CO}_{2}$ (dry) reforming or by conversion with $\mathrm{O}_{2}$ through secondary reforming and partial oxidation [4]. Three main methane steam reforming reactions are always carried out as presented in the following equations:

$$
\begin{aligned}
\mathrm{CH}_{4}+\mathrm{H}_{2} \mathrm{O} & \leftrightarrow 3 \mathrm{H}_{2}+\mathrm{CO} \\
\mathrm{CO}+\mathrm{H}_{2} \mathrm{O} & \leftrightarrow \mathrm{CO}_{2}+\mathrm{H}_{2} \\
\mathrm{CH}_{4}+2 \mathrm{H}_{2} \mathrm{O} & \leftrightarrow \mathrm{CO}_{2}+4 \mathrm{H}_{2}
\end{aligned}
$$

Both water-gas shift reaction (Eq. (2)) and reverse methanation (Eq. (3)) are associated with the steam reforming over a catalyst at elevated temperatures [5]. Steam reforming reactions are usually carried out on supported nickel catalysts. Nickel is cheap and sufficiently active, and allows suitable catalysts to be economically produced.

Nickel steam-reforming catalysts are subject to several deactivation mechanisms including coking, poisoning, and sintering. Sintering is the process of agglomeration of the crystallites of the active phase, which leads to loss of active surface and, consequently, a decrease in activity. The sintering process is influenced by many parameters, among which the temperature and the atmosphere over the catalysts are the most important ones. Sintering rates increase strongly with temperature and are particularly large in the presence of water [6]. Another major problem in the application of these catalysts is sulfur poisoning. Even after a thorough desulfurization of the feedstock, sulfur-containing compounds in the feed may reach the nickel catalyst at a $\mathrm{ppb}$ level. Sulfur, as a strong poison for nickel catalysts, easily blocks the active nickel sites. The sulfur adsorption capacity of steam-reforming catalysts is therefore an important catalyst parameter [7].

The aggregation of metal particles necessarily involves the transport of metals within the catalyst. Two mechanisms for the metal particle growth have been proposed: (i) particle migration, where entire crystallites migrate over the support, followed by coalescence, (ii) Ostwald ripening (atom migration or vapor transport), where metal transport species emitted from one crystallite, migrate over the support or via the (gas) phase and are captured by another crystallite [7]. It is very difficult to determine whether this occurs by the migration of metal atoms (Ostwald ripening) or by crystallite migration and coalescence. 
The most common cause of poisoning involves strong chemisorptions of gas phase species on the active sites. If the chemisorptions are weak, desorption and reactivation may occur. However, the catalyst deactivates if the chemisorptions are strong. The effectiveness of a poison depends on the equilibrium constant for the poisoning reaction and on the catalyst activity of the product formed. Sulfur is a good case in point.

Sulfur is a severe and common poison for nickel steam reforming catalysts as a sulfur-poisoned nickel catalyst has essentially no activity below $700{ }^{\circ} \mathrm{C}$. All sulfur-containing compounds in the feed are converted into hydrogen sulfide under reforming conditions [7]. The sulfur atom in hydrogen sulfide adsorbs strongly at the nickel surface by the following reaction:

$$
\mathrm{H}_{2} \mathrm{~S}+\mathrm{Ni}_{\text {Surface }} \leftrightarrow \mathrm{Ni}_{\text {Surface }}-\mathrm{S}+\mathrm{H}_{2}
$$

Equation (4) is a fast, reversible process in a large range of concentration. Feedstock with $\mathrm{S}$ contents lower than 10 $\mathrm{ppb}$ are recommended to avoid appreciable deactivation of the Ni catalytic surface [8]. Process (4) is carried out simultaneously with adsorption of water at active sites (Eq. (5)).

$$
\mathrm{H}_{2} \mathrm{O}+\mathrm{Ni}_{\text {Surface }} \leftrightarrow \mathrm{Ni}_{\text {Surface }}-\mathrm{O}+\mathrm{H}_{2}
$$

Steam content in feed competes with sulfur in binding the active sites. The crystalline structure and the nature of support may contribute to the sulfur poisoning [9-11], so the type of support may have an influence on reversibility of sulfur poisoning.

The objective of this work is to determine deactivation circumstances and also to deal with regeneration of deactivated catalysts.

\section{Experimental}

\subsection{Catalyst preparation and reaction tests}

The commercial catalysts are supplied by Arak and Razi petrochemical complexes (Iran). Ni supported on calcium aluminate phase is an industrial steam methane reforming catalyst. The catalyst was crushed and sieved to the appropriate size (30-50 mesh).

The experimental setup used for these experiments was operated at atmospheric pressure with a ratio of methane to steam of $\mathrm{CH}_{4} / \mathrm{H}_{2} \mathrm{O}=1 / 3$, and the flow rates of components were $\mathrm{CH}_{4} 4.176 \mathrm{ml} / \mathrm{min}, \mathrm{H}_{2} \mathrm{O}$ (liquid) $0.001 \mathrm{ml} / \mathrm{min}$, and $\mathrm{N}_{2}$ $33.3 \mathrm{ml} / \mathrm{min}$. High purity methane (no less than $99.99 \%$ ) was used as the reactant. Runs were carried out in a fixed-bed quartz micro reactor (6.6 mm ID). After loading of the catalyst $(200 \mathrm{mg}$ ), the catalyst was reduced in situ for $2 \mathrm{~h}$ in a $50 \mathrm{~mol} \% \mathrm{H}_{2}-50 \mathrm{~mol} \% \mathrm{~N}_{2}$ mixture $(60 \mathrm{ml} / \mathrm{min})$ with the temperature raised from ambient to $600{ }^{\circ} \mathrm{C}$ at a rate of $10{ }^{\circ} \mathrm{C} / \mathrm{min}$, due to that a part of the $\mathrm{Ni}$ in the fresh catalysts is found as $\mathrm{NiO}$ from the XRD study. The catalyst was then heated to $850{ }^{\circ} \mathrm{C}$ under the nitrogen flow with the rate of temperature increase of $10{ }^{\circ} \mathrm{C} / \mathrm{min}$. Water and methane were then introduced to the reactor, respectively. The composition of the gas stream out of the reactor (including remaining $\mathrm{CH}_{4}$ and produced $\mathrm{CO}, \mathrm{CO}_{2}$, and $\mathrm{H}_{2}$ ) was determined by gas chromatography. The remaining water vapor exiting the reactor was removed from the product stream by use of a condenser.

\subsection{Catalyst characterization}

X-ray diffraction (XRD) studies were performed in a PW-1800 Philips diffractometer with $\mathrm{Cu} K_{\alpha}$ radiation $(\lambda=$ $0.15406 \mathrm{~nm}$ ) at $40 \mathrm{kV}$ and $30 \mathrm{~mA}$ for determining crystalline phases. The crystalline phases were identified by comparison with the Joint Committee on Powder Diffraction Standards (JCPDS) files (PCPDFWIN version 1.30, August 1997). Particle-size estimates for the fresh, spent (used), and regenerated samples were calculated from the experimental line broadening (line width at half maximum, FWHM) of the characteristic Ni reflection using the Debye-Scherrer equation.

Chemical analysis of all samples was carried out using a scanning electron microscope (SEM) coupled with an energy dispersive spectroscopy (EDS) analysis for the determination of chemical composition of the samples. SEM images were taken on a Philips XL30 microscope.

The amount of deposited carbon and sulfur on species after reaction was quantified by carbon analysis (CA) performed on a thermal analysis Leco CS-444 from ambient to burned sample temperature. The samples burnt in oven and amount of gas outlet was determined by a quadruple mass spectrometer.

Transmission electron microscopy (TEM) images directly yield the size and shape of the nickel particles. TEM measurements were done on a Philips CM200 FEG (Field Emission Gun) electron microscope with a primary electron energy of $200 \mathrm{keV}(\lambda=0.002507 \mathrm{~nm})$ and a point resolution of $0.19 \mathrm{~nm}$ in TEM mode.

\subsection{Regeneration treatments}

The regeneration process for Arak and Razi Petrochemical samples was performed in an attempt to redisperse agglomerated nickel particles and remove both sulfur and carbon from the Ni catalyst, using the carbon dioxide and steam treatment in $700{ }^{\circ} \mathrm{C}$, respectively. It should be noted that high temperature would increase risk of sintering in regeneration process. The regeneration treatments were carried out for $2 \mathrm{~h}$. Furthermore, in order to remove sulfur from Razi specimen, hydrogen was added to the steam to prevent a fully oxidative atmosphere, and repetitious reduc- 
tion of catalyst before reforming reaction should be avoided. After each satisfactory treatment the catalyst was cooled under nitrogen down to room temperature. Afterwards, each sample was sent to determine sulfur and carbon content and calculate nickel particle size by TEM graph.

\section{Results and discussion}

\subsection{Catalyst characterization}

In this paper, we have an industrial nickel catalysts used for production of synthesis gas with $\mathrm{H}_{2} / \mathrm{CO}=3 / 1$ ratio. Two supported nickel catalysts were studied. Arak and Razi petrochemical catalysts both contain $18 \mathrm{wt} \% \mathrm{Ni}$, supported on a calcium aluminates carrier.

\subsubsection{Characteristics of Arak petrochemical complex catalyst}

We have a unique situation in Arak petrochemical complex as carbon dioxide is introduced into the feed stream to reduce the $\mathrm{H}_{2} / \mathrm{CO}$ ratio. The catalyst remains under severe thermal conditions at $900{ }^{\circ} \mathrm{C}$, and it becomes unusable after approximately four years of operating.

The XRD patterns of the Arak samples are shown in Fig. 1. $\mathrm{NiO}$ gives peaks at $2 \theta=37.249^{\circ}$ and $43.276^{\circ}$. According to the comparison of $\mathrm{NiO}$ phase from XRD patterns for the fresh and used catalysts, we can find out an agglomeration of nickel particle in the used sample (Fig. 1). This is based on the intensity and width at the half-height of the $\mathrm{NiO}$ peaks, taking into consideration that the crystallite size gets smaller when the peak gets broader. The average size of the

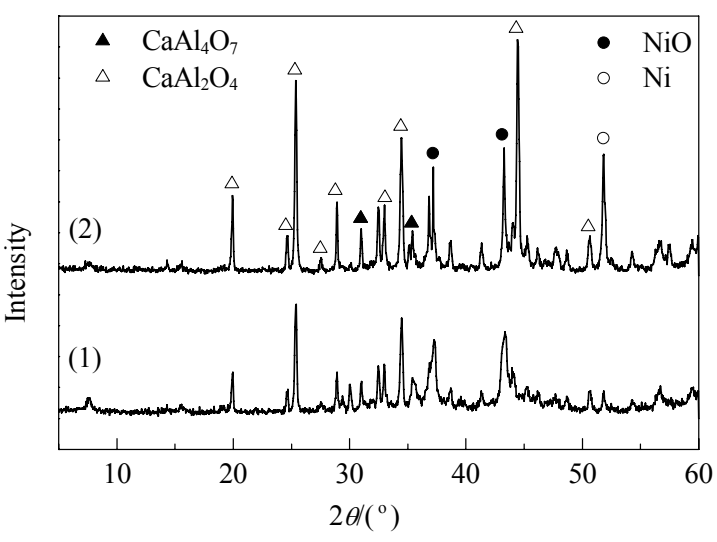

Fig. 1. XRD patterns of fresh (1) and used (2) Ni/CaAl ${ }_{m} \mathrm{O}_{n}$ catalysts from Arak petrochemical complex.

nickel oxide calculated by means of the Debye-Scherrer equation is about 12 and $96 \mathrm{~nm}$ for fresh and used catalysts, respectively. High temperature of the reaction $\left(>900{ }^{\circ} \mathrm{C}\right)$ accelerated sintering of nickel particle. Moreover, the XRD pattern of the used catalyst reveal a metallic $\mathrm{Ni}$ at $2 \theta=$ $51.84^{\circ}$.

Although no separate diffraction lines of non-reduced $\mathrm{Ni}^{2+}$ species are in the form of $\mathrm{NiAl}_{2} \mathrm{O}_{4}$ spinel could be observed in the XRD diagrams at high temperature, the presence of Ni-aluminate cannot be completely excluded. On the other hand, it indicates that this support is very effective at high reaction temperature, as shown in Fig. 1. The amount of coke and sulfur deposited in the spent catalyst is about 0.13 and $0.03 \mathrm{wt} \%$, respectively, as measured by carbon and sulfur analysis.

Furthermore, EDS spectra shown in Fig. 2, show an in-
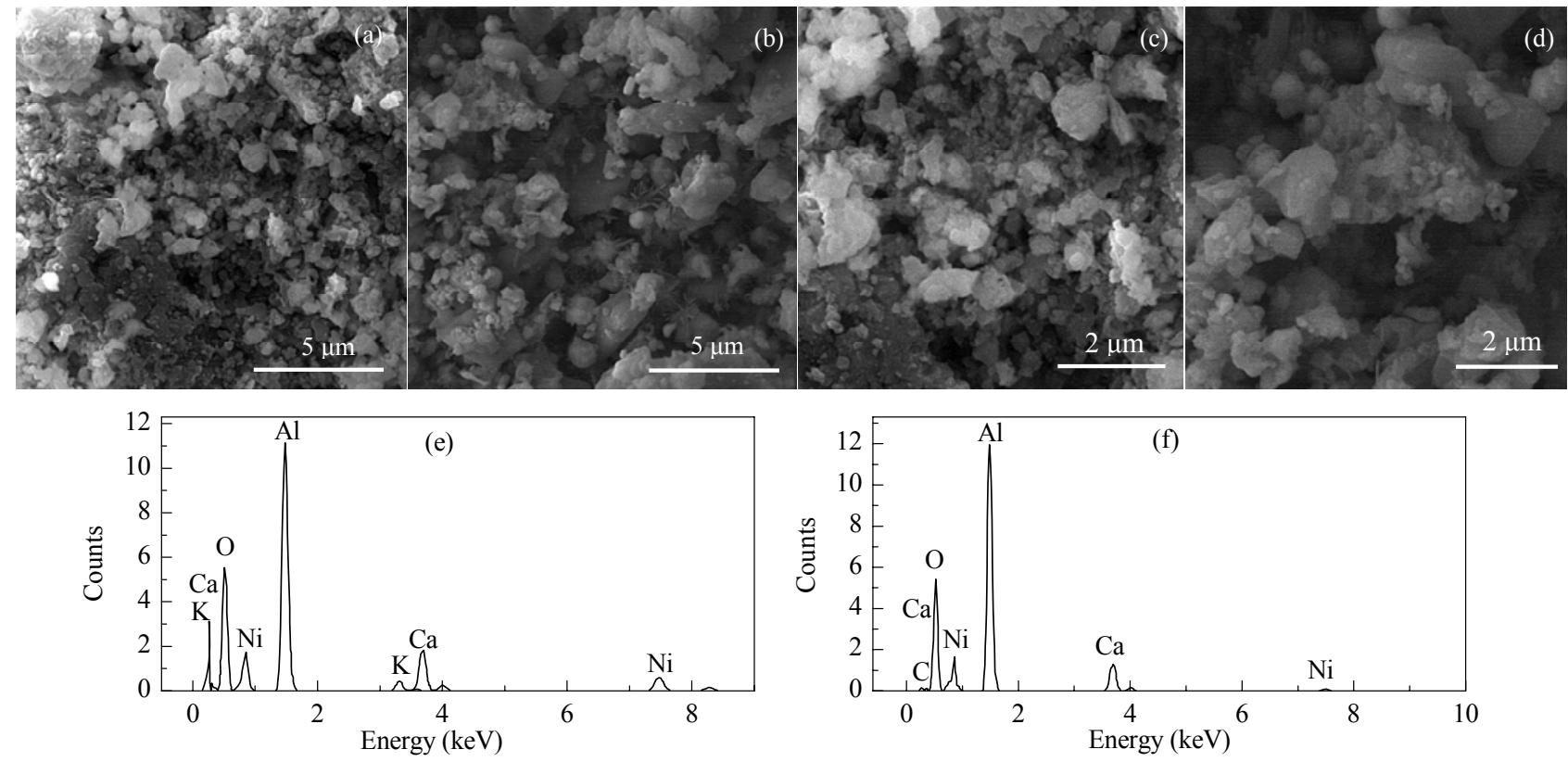

Fig. 2. EDS and SEM images of fresh (a, c, e) and used (b, d, f) catalyst samples from Arak petrochemical complex. 
crease in nickel particle's diameter, in agreement with the XRD results. Besides, EDS test result at four different locations on catalyst surface shows that the average weight percentage of nickel content in used and fresh sample are 13.10 and $2.70 \mathrm{wt} \%$, respectively (Table 1), which means the agglomeration of Ni species on support for the used sample.

Table 1 The percentage of nickel contents at four different positions on catalyst surface of Arak petrochemical sample by EDS

\begin{tabular}{lcc}
\hline \multirow{2}{*}{ Position } & \multicolumn{2}{c}{ Ni content $(\mathrm{wt} \%)$} \\
\cline { 2 - 3 } & Fresh sample & Used sample \\
\hline Point 1 & 12.70 & 3.47 \\
Point 2 & 12.32 & 1.99 \\
Point 3 & 13.60 & 1.94 \\
Point 4 & 13.70 & 3.44 \\
Average & 13.08 & 2.71 \\
\hline
\end{tabular}

SEM micrographs (Fig. 2) reveal the presence of carbon in the used catalyst, in agreement with the carbon analysis of this sample $(0.13 \mathrm{wt} \%)$, but it is not as much as the case of sintering.

On the basis of above descriptions we can draw a conclusion that the main cause of the catalyst deactivation is ascribed to thermal sintering of nickel particles rather than carbon formation or deposition of sulfur poison.

The lack of a carbon peak (at $2 \theta=26.4^{\circ}$ ) in the XRD patterns of tested samples confirms the high coking resistivity of this Ni catalyst, which is consistent with the carbon analysis results.

\subsubsection{Characteristics of Razi petrochemical complex catalyst}

In this case we have nickel catalyst used for production of synthesis gas with $\mathrm{H}_{2} / \mathrm{CO}=3 / 1$ ratio.

There are three deactivated catalysts from top, middle, and bottom of tower. As we know, one of the unexpected problems is excessive concentration of sulfur and sulfur derivations in feed gas. Sulfur is a strong poison for nickel catalysts by blocking the active nickel sites. The reaction conditions employed here are rather severe in terms of sulfur and carbon deposition. Sulfur and carbon contents in three deactivated catalysts are summarized in Table 2. It clearly shows the huge amount of sulfur and carbon in catalyst at top of the tower. The fact that the catalysts in the middle and bottom of tower contain much less sulfur indicates that sulfur content of the feed was dramatically increased.

The XRD patterns of the deactivated samples in top, middle, and bottom of the tower are shown in Fig. 3. NiO gives a peak at $2 \theta=37.25^{\circ}$, and no indication of $\mathrm{NiAl}_{2} \mathrm{O}_{4}$ is observed for this catalyst. Figure 3 clearly points out that
Table 2 Sulfur and carbon weight percentage of nickel catalyst at top, middle, and bottom of tower in Razi petrochemical complex

\begin{tabular}{lcc}
\hline \multirow{2}{*}{ Tower } & \multicolumn{2}{c}{ Content $(w t \%)$} \\
\cline { 2 - 3 } & Carbon & Sulfur \\
\hline Top & 0.17 & 0.21 \\
Middle & 0.04 & 0.03 \\
Bottom & 0.03 & 0.03 \\
\hline
\end{tabular}

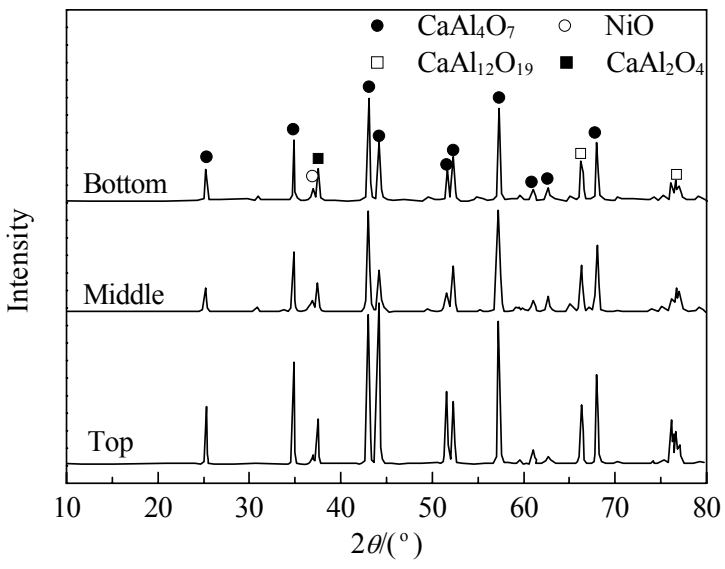

Fig. 3. XRD patterns of active and support phases for top, middle, and bottom of tower catalyst sample in Razi petrochemical complex.

calcium aluminate used as support. The results demonstrate that there are no considerable changes of nickel crystallite sizes by comparing three deactivated catalysts and the fresh one. Sharpening up for support phase at top of the tower indicates that particles of calcium aluminate became larger, which is consistent with the SEM micrographs of these samples as shown in Fig. 4.

\subsection{Catalyst regeneration processes}

\subsubsection{Arak sample}

Regeneration tests were carried out in a mixture of an oxidation gas $\left(\mathrm{CO}_{2}, \mathrm{H}_{2} \mathrm{O}, \mathrm{O}_{2}\right)$ and $\mathrm{N}_{2}$ as carrier gas with a volume ratio of $\left(\mathrm{CO}_{2}+\mathrm{H}_{2} \mathrm{O}+\mathrm{O}_{2}\right) / \mathrm{N}_{2}=1 / 9$ at a total rate of $100 \mathrm{ml} / \mathrm{min}$, at atmospheric pressure in a tubular fixed-bed reactor, at a temperature of $700{ }^{\circ} \mathrm{C}$. Prior to regenerating of the catalyst, the reaction was carried out to determine its activity. Initial methane conversion and hydrogen yield for fresh and used catalysts obtained are $88 \%, 91 \%$ and $25 \%$, $21 \%$, respectively. It can be observed that the Ni-based catalyst performance is not significantly affected by oxygen and steam regeneration stream in terms of methane conversion and hydrogen yield. On the other hand, for the treatment by carbon dioxide, the catalyst regained $76 \%$ of its activity. $\mathrm{CH}_{4}$ conversion and $\mathrm{H}_{2}$ selectivity over regenerated nickel catalyst in a flow of $\mathrm{CO}_{2}$ reach $73 \%$ and $82 \%$, respectively. 

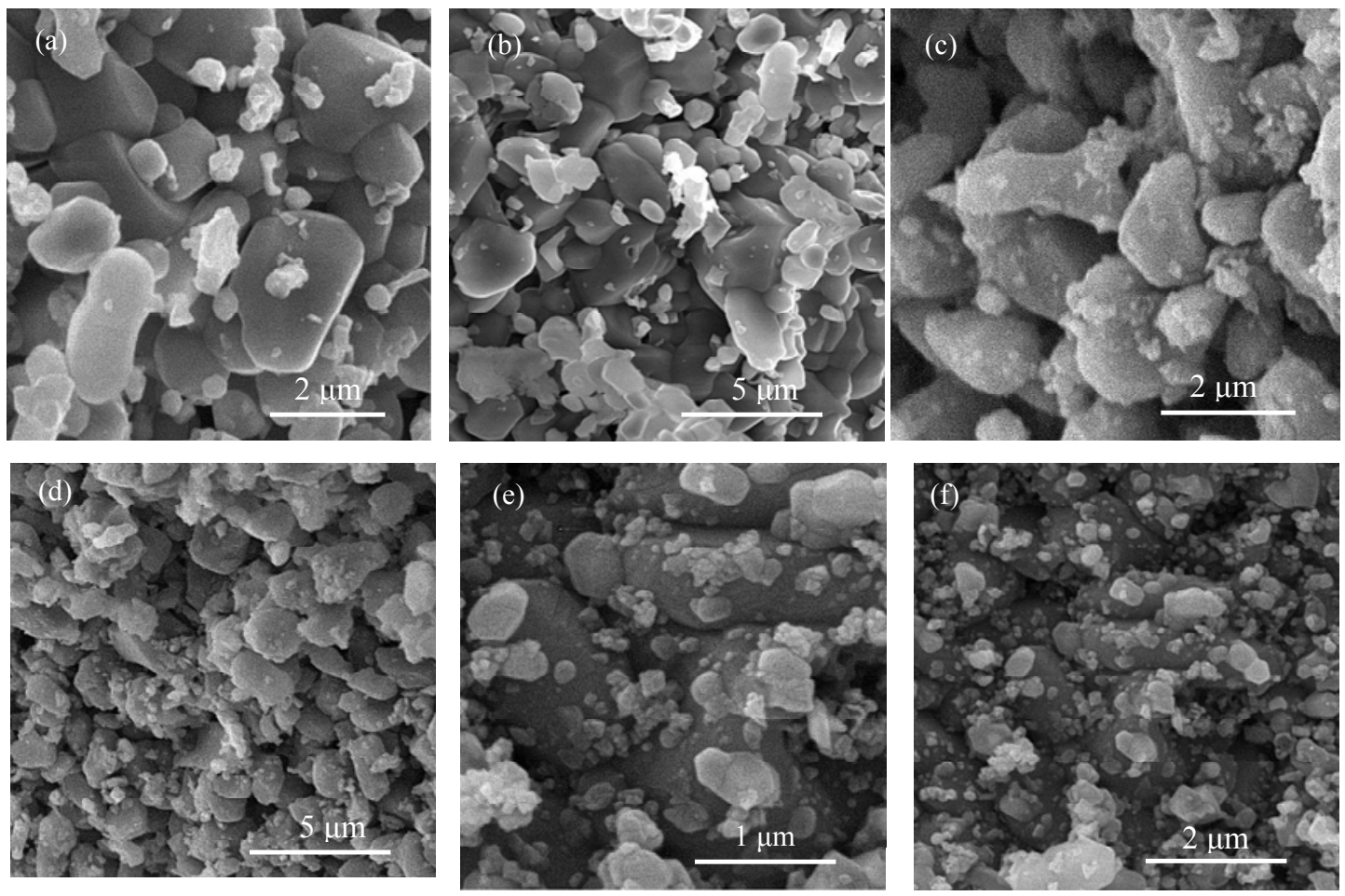

Fig. 4. SEM images of bottom $(a, b)$, middle (c, d), and top (e, f) of used catalyst sample in Razi petrochemical complex.

The XRD profile of regenerated catalyst with $\mathrm{CO}_{2}$ stream is shown in Fig. 5 (the sample passivated after regeneration by cooling in $\mathrm{N}_{2}$ flow at room temperature). It reveals the presence of $\mathrm{NiO}$ and $\mathrm{Ni}$ as the nickel-containing crystalline phases for the regenerated catalyst. Their respective XRD patterns reveal two prominent reflections at $2 \theta=37.23^{\circ}$ and $43.28^{\circ}$, assigned to nickel oxide. The regenerated catalyst shows weaker and broader nickel diffraction peaks, which can be attributed to a reducing of nickel particle size. The average size of the nickel oxide calculated by means of the Debye-Scherrer equation is about $23 \mathrm{~nm}$ for regenerated catalyst, comparing to $96 \mathrm{~nm}$ for the used catalyst. It should

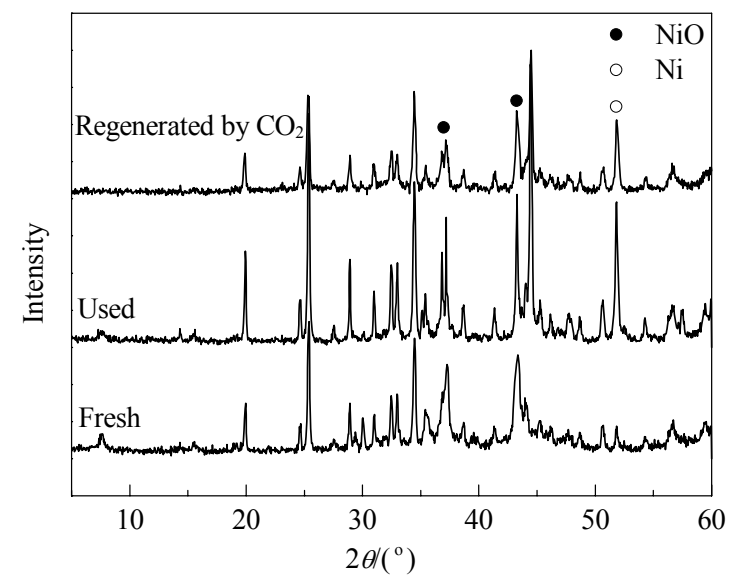

Fig. 5. XRD patterns of Ni catalysts before and after treatment with $\mathrm{CO}_{2}$ stream in comparison with fresh one. be noted that XRD analyses indicate no structure changes in the nickel particles as the catalyst is regenerated by $\mathrm{CO}_{2}$ stream. Additionally, no carbon species content were detected by carbon analyzer.

In the attempt to rationalize the catalytic patterns, homogeneous and well-defined spherical particles are evidenced by TEM. The NiO crystal size found from TEM images agrees well with the results from XRD. The images of the regenerated and sintered samples are shown in Fig. 6. Although particle sizes derived from TEM and XRD in general show the same trends, there are some discrepancies between the particle sizes found with different techniques, due to the limitations of each one.

On the basis of the above results discussed, it can be concluded that the redispersion of agglomerated nickel particle can be realized in a flow of $\mathrm{CO}_{2}$ as a partial oxidation stream.

\subsubsection{Razi sample}

Regeneration of the nickel catalyst was shown to be effective upon injection of steam stream at $700{ }^{\circ} \mathrm{C}$. Following reactions take place on catalyst surface with steam along with $\mathrm{H}_{2}$ gas.

$$
\begin{aligned}
\mathrm{Ni}_{\text {Surface }} \mathrm{S}+\mathrm{H}_{2} \mathrm{O} & \leftrightarrow \mathrm{NiO}+\mathrm{H}_{2} \mathrm{~S} \\
\mathrm{NiO}+\mathrm{H}_{2} & \leftrightarrow \mathrm{Ni}+\mathrm{H}_{2} \mathrm{O} \\
\mathrm{Ni}_{\text {Surface }} \mathrm{S}+\mathrm{H}_{2} & \leftrightarrow \mathrm{H}_{2} \mathrm{~S}+\mathrm{Ni} \\
\mathrm{H}_{2} \mathrm{~S}+2 \mathrm{H}_{2} \mathrm{O} & \leftrightarrow \mathrm{SO}_{2}+3 \mathrm{H}_{2}
\end{aligned}
$$



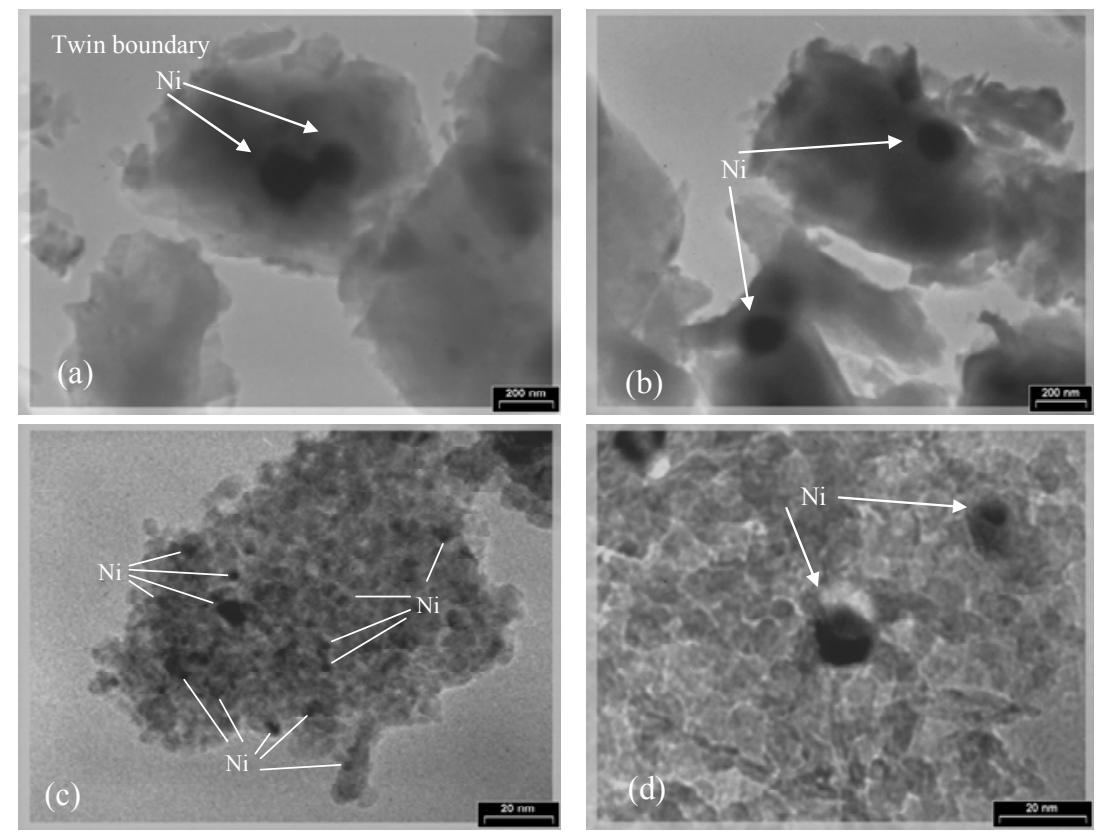

Fig. 6. TEM images of used $(a, b)$ and regenerated by $\mathrm{CO}_{2}$ at $700{ }^{\circ} \mathrm{C}(\mathrm{c}, \mathrm{d})$ catalyst samples in Razi petrochemical complex.

The presence of $\mathrm{H}_{2}$ gas in steam stream causes the prevention of additional reduction in methane reforming reaction (Eq. 7) and also desulphurization of nickel surface according to Eq. 8. Furthermore, the value of $\mathrm{H}_{2}$ in treatment should be adequate, because increasing the amount of $\mathrm{H}_{2}$ may diminish the efficiency of regeneration process (Eqs. 6 and 9).

The data in Fig. 7 show the impressive results in sulfur removal from $\mathrm{Ni}$ based catalyst. The degree of regeneration is declared with the ratio $\mathrm{S} / \mathrm{S}_{0}, \mathrm{~S}$ and $\mathrm{S}_{\mathrm{o}}$ are the sulfur contents after regeneration treatment and in initial deactivated catalyst, respectively, where for the carbon content is kept same. We can see the profound changes in sulfur content in regenerated catalyst.

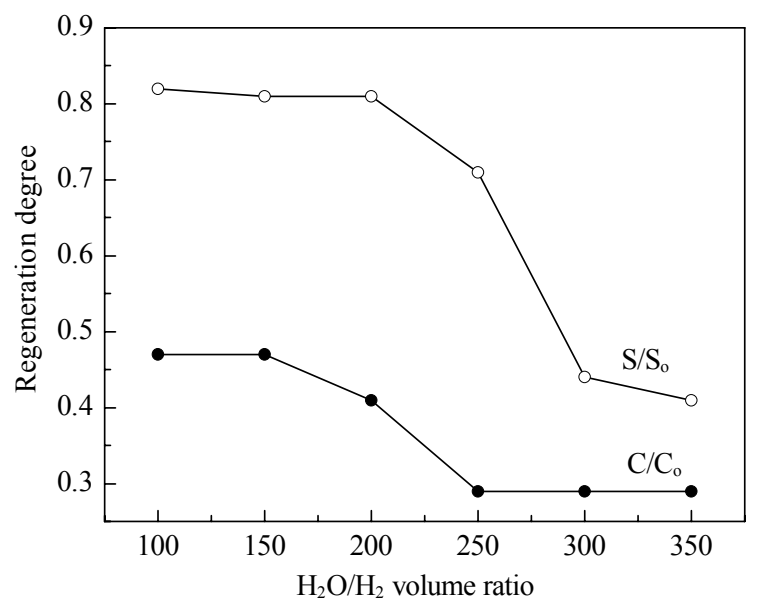

Fig. 7. Results in regeneration treatment with $\mathrm{H}_{2} \mathrm{O} / \mathrm{H}_{2}$ for removing sulfur and carbon in contaminated Ni-based catalyst.
When the ratio $\mathrm{H}_{2} \mathrm{O} / \mathrm{H}_{2}$ was initially increased, no improvement was observed as expected from the chemisorptions experiment. However, when $\mathrm{H}_{2} \mathrm{O} / \mathrm{H}_{2}$ ratio was increased to above 200 a significant decrease of sulfur content in regenerated catalyst was observed (Fig. 7). Surprisingly there is the similar condition for the removal of carbon deposition as shown Fig. 7. One of the characteristics of this treatment is that the catalyst structure does not change significantly during the regeneration process, as shown in Fig. 8.

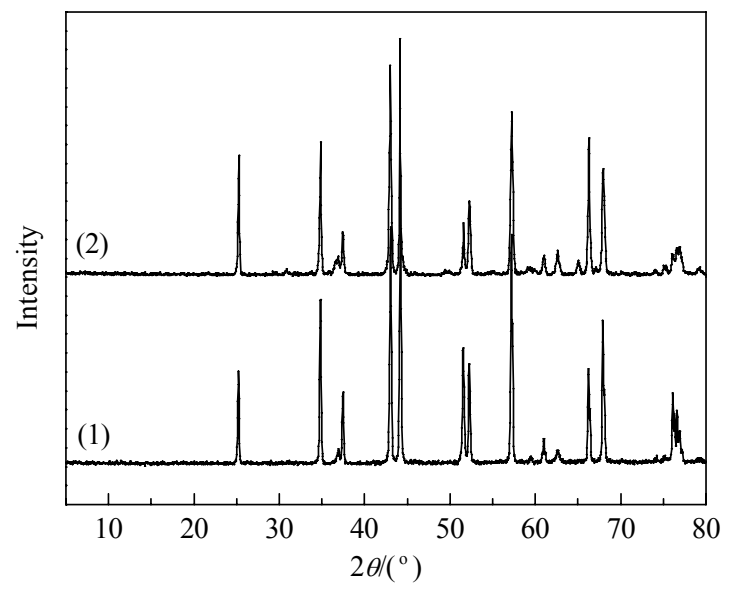

Fig. 8. XRD patterns of Ni catalysts before (1) and after (2) treatment with steam.

The observed methane conversions for the catalyst before and after regeneration are summarized in Fig. 9. The catalyst regained more than $80 \%$ of its activity at $\mathrm{H}_{2} \mathrm{O} / \mathrm{H}_{2}$ ratio of 350 . 


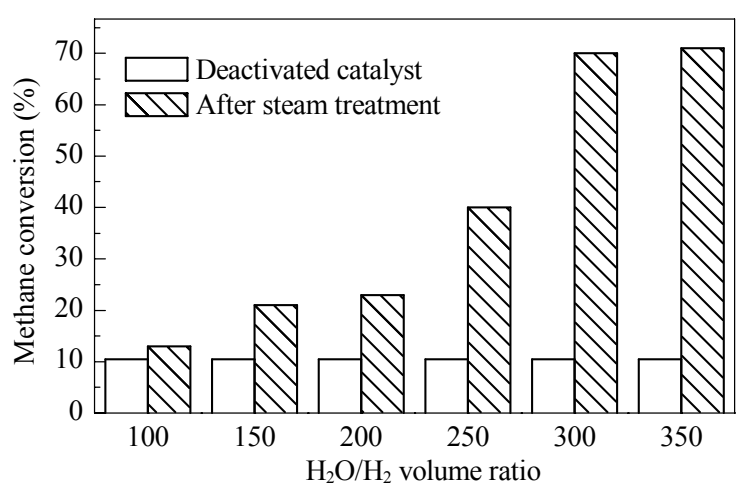

Fig. 9. Methane reforming conversion on nickel catalyst before and after treatment with steam.

\section{Conclusions}

Two industrial nickel-based catalysts used in Arak and Razi petrochemical complexes (Iran) were studied. The most important factors in deactivation of the catalyst are the agglomeration of nickel particle and sulfur poisoning. In an attempt to redisperse nickel particles, deactivated Arak catalyst was regenerated at $700{ }^{\circ} \mathrm{C}$ with $\mathrm{CO}_{2}$ as oxidative atmosphere. The regenerated sample shows a significant increase in methane conversion and hydrogen yield up to $73 \%$ and $82 \%$, respectively. XRD analyses of the regenerated samples indicate no apparent structural changes. Particle size derived both from XRD patterns and TEM images are in well agreement, showing the decreasing of $\mathrm{NiO}$ particle size. These results indicate that the decreasing of the sintered-Ni particles size is a key factor to improve the catalytic performance of the Ni-based catalyst. For Razi specimen, the regeneration process is based on an oxidative removal of sulfur and carbon from the deactivated catalyst with steam treatment at $700{ }^{\circ} \mathrm{C}$. Since most of the sulfur and carbon is thereby removed, catalyst regained more than $80 \%$ of its activity. More importantly, there are no obvious changes of the crystal structure as detected by XRD.

\section{Acknowledgments}

The authors would like to express their gratitude to Arak and Razi petrochemical complexes for providing the $\mathrm{Ni}$ catalysts.

\section{References}

1 Rasmussen F B, Sehested J, Teunissen H T, Molenbroek A M, Clause B S. Appl Catal A, 2004, 267: 165

2 Armor J N. Appl Catal A, 1999, 176: 159

3 Villacampa J I, Royo C, Romeo E, Montoy J A, Angel P D, Monzóna A. Appl Catal A, 2003, 252: 363

4 Rostrup-Nielsen J R. Catal Today, 1993, 18: 305

5 Laosiripojana N, Assabumrungrat S. Appl Catal A, 2005, 290: 200

6 Bartholomew C H, Sorensen W L. J Catal, 1983, 81: 131

7 Sehested J. Catal Today, 2006, 111: 103

8 Lombard C, Doze S L, Marencak E, Marquaire P-M, Noc D L, Bertrand G, Lapicque F. Inter J Hydrogen Energy, 2006, 31: 437

9 Hubbard C P, Otto K, Gandhi H S, Ng K Y S. J Catal, 1993, 144: 484

10 Hubbard C P, Otto K, Gandhi H S, Ng K Y S. J Catal, 1995, 30: 41

11 Waqif M, Baxin P, Saur O, Lavalley J C, Blanchrd G, Touret O. Appl Catal B, 1997, 11: 193 